\title{
Stem cells and cell therapy: From basic sciences to clinical perspectives
}

\author{
Luciana Machado $^{1}$, Arnaldo Rodrigues Santos Jr. ${ }^{2}$ \\ ${ }^{1}$ Centro Regional Universitário de Espírito Santo do Pinhal, Espírito Santo do Pinhal, SP, Brazil \\ ${ }^{2}$ Centro de Ciências Naturais e Humanas, Universidade Federal do ABC, Santo André, SP, Brazil \\ Email: arnaldo.santos@ufabc.edu.br
}

Received 6 April 2013; revised 13 May 2013; accepted 26 May 2013

Copyright (c) 2013 Luciana Machado, Arnaldo Rodrigues Santos Jr. This is an open access article distributed under the Creative Commons Attribution License, which permits unrestricted use, distribution, and reproduction in any medium, provided the original work is properly cited.

\begin{abstract}
Stem cells are seen as a possible solution for organ and tissue regeneration and for the treatment or even cure of various diseases. There are basically two types of stem cells: embryonic and adult stem cells. Embryonic stem cells are derived from embryos and exhibit an extensive multiplication and differentiation potential. On the other hand, adult stem cells, which are found in bone marrow and other tissues, have a lower multiplication and differentiation capacity but are more easily isolated and applied. In adult stem cell therapies using bone marrow or umbilical cord blood transplantation, the differentiation of a certain cell type is induced and its multiplication is stimulated, followed by the implantation of these cells into damaged tissues. Examples of the application of stem cells include the treatment of autoimmune diseases such as type 1 diabetes mellitus and heart diseases. Stem cells open up new prospects for the treatment of a series of diseases. In this respect, basic knowledge of the mechanisms of growth and differentiation of these cells is of the utmost importance to optimize therapeutic results. In this review, we discuss the mechanisms of stem cell differentiation and describe the clinical results reported in the literature, mainly by Brazilian research groups.
\end{abstract}

Keywords: Stem Cells; Cell Differentiation; Cell Transplantation; Cell Therapy

\section{INTRODUCTION}

We are currently witnessing the advent of a fascinating and promising therapeutic modality, the use of stem cells (SCs) for the regeneration of damaged tissues, once considered to be irreparable. Promising results from experi- mental animal studies have encouraged groups from different centers all over the world to start clinical trials that investigate the feasibility of SC transplantation for the treatment of various diseases [1]. SCs possess two important characteristics: they are not specialized and they are able to renew themselves for long periods of time under certain physiological or experimental conditions. In addition, SCs can be induced to acquire special functions, i.e., they are able to differentiate into other cell types [2].

The control of this process of differentiation is one of the major challenges of current research. Some aspects of this process are already known. For example, studies using genetic techniques have identified some basic characteristics responsible for the maintenance of the undifferentiated state based on the gene expression pattern of these cells. These characteristics include the capacity to respond to hormones and growth factors, extracellular matrix, and high resistance to stress through the increased expression of DNA repair enzymes [1].

The objective of the present review was to describe the relevant aspects of cell therapy, including basic concepts of SCs, as well as the main experimental studies and clinical data, focusing mainly on the results reported by Brazilian research groups. In addition, we discuss the uncertainties that surround the behavior and use of SCs.

\section{MATERIALS AND METHODS}

A review of papers published mainly by Brazilian research groups was performed using the public database Scientific Electronic Library Online-SciELO

(www.scielo.br). The Medline and Literatura LatinoAmericana e do Caribe em Ciências da Saúde (LILACS) systems, both available at the Virtual Health Library of search. Finally, some papers retrieved from the international PubMed database 
(http://www.ncbi.nlm.nih.gov/pubmed) were also analyzed. The following keywords were used in all searches: stem cells, cell therapy, orthopedics, cardiology, rheumatology, and dentistry.

\section{RESULTS AND DISCUSSION}

\subsection{General Characteristics of Stem Cells}

The most important characteristics that define SCs are: a) the capacity of self-renewal, which confers the potential to live and proliferate indefinitely, and b) the capacity of differentiation. Embryonic stem cells (ESCs) are derived directly from the pluripotent tissues of preimplantation embryos. These cells receive the status pluripotent because they can be expanded in cell culture, maintaining their pluripotent characteristics and giving rise to different cell types found in the embryo and in the adult organism. ESCs are often described as totipotent since they give rise to the embryonic germ layers (endoderm, mesoderm, and ectoderm). However, ESCs derived from the blastocyst are unable to generate all cell types. In particular, these cells do not generate trophectoderm cells. In addition, these cells cannot regenerate a blastocyst and can therefore not produce a complete embryo. Thus, the term totipotent should only be applied to the zygote and blastomeres during the early stages of cleavage [3].

In adults, SCs persist in some tissues and play a role in the process of tissue renewal throughout the life of an individual. Tissue renewal is necessary since many cells lose the capacity of mitotic division, once they reach their final differentiation. The cells that are lost during the life of an individual are replaced with a population, called adult stem cells (ASCs). ASCs are defined as a poorly differentiated cell population, i.e., cells with a high differentiation potential present in an adult organism. When dividing, these cells produce two distinct populations: the first remains undifferentiated like its progenitor and the second differentiates into some specialized cell [4].

Among postnatal tissues harboring SCs, bone marrow has been widely studied as a source of both hematopoietic stem cells (HSCs) and mesenchymal stem cells (MSCs). However, the latter can also be found in other tissues [5,6]. MSCs derived from human bone marrow are also called skeletal SCs, bone marrow stromal cells, or multipotent mesenchymal stromal cells [5]. Despite the variable nomenclature, MSCs comprise a group of cells present in the bone marrow stroma that are able to differentiate into different mesodermal cell lines and, possibly, other types of non-mesodermal cells. MSCs are found in the stromal fraction of bone marrow, which provides a microenvironment that sustains hematopoiesis. It is believed that these cells provide stromal support for the growth and differentiation of HSCs and for hemato- poiesis itself. In fresh adult marrow, MSCs account for approximately $0.01 \%$ to $0.0001 \%$ of all nucleated cells [5].

\subsection{Embryonic Stem Cells}

The isolation of human ESCs was reported for the first time in 1998. Since then, the number of studies on the improvement of culture conditions, genetic manipulation and induction of differentiation into different tissues has grown exponentially [1,7]. ESCs are pluripotent and can give rise to all types of cells of the organism. At less than one week after fertilization, the developing embryo contains between 100 and 150 cells and forms a hollow sphere, the blastocyst. The latter is made up of a single outer cell layer, which generates the extraembryonic membrane, and an inner cell mass, which gives rise to the embryo itself. By the third week, the embryo reaches the gastrula stage. In this stage, three distinct germ layers are established, which subsequently form the different types of cells and tissues [8]. The control of the differentiation of these cells is difficult, but the environmental conditions, growth factors and other proteins necessary to guide the differentiation into stable cells are now starting to be understood [4].

ESCs are isolated by transfer of the inner cells mass to a culture medium where they multiply on a layer of feeder layer cells, normally obtained from mouse skin, which have been treated so that they no longer multiply. Feeder layer cells permit adhesion to the inner cell mass by secreting nutrients into the culture medium. The cells of the inner mass then proliferate for various days. These cells can be frozen, kept in culture, or used in experiments. The cells can also be maintained undifferentiated under certain conditions; however, once these cells are cultured together to form embryoid bodies, i.e., ESC aggregates, they begin to differentiate spontaneously [9].

The obstacles to SC use that need to be overcome include: a) the development of more effective techniques for the isolation of SCs, b) the improvement of methods for the identification of ESCs and their developmental potential, c) tools to control the differentiation and growth of SCs in the body, and d) a better understanding of the advantages of ESCs over ASCs in different applications [2].

\subsection{Adult Stem Cells}

ASCs, also known as somatic stem cells, are classically recognized to differentiate only into cells of their tissue of origin. The role of ASCs in the organism is to maintain and repair the tissues in which they are found [10, 11]. ASCs are found in various tissues, but stem cells derived from red bone marrow and adipose tissues are most frequently used in clinical practice [12]. A potential 
advantage of ASCs is that they can be expanded in culture and then reintroduced into the same patient, thus preventing rejection by the immune system. ASCs are believed to remain quiescent in the tissues in which they are found until they are activated by diseases, tumors, or injuries. In addition, these cells replace cells of the organism throughout life by the release of progenitor cells into the blood circulation, which migrate to the sites where they are needed [13].

In the 1960s, researchers discovered that the bone marrow contains two populations: one population of HSCs that form blood cells in the organism, and a second mixed population, called bone marrow stromal cells, that can generate bone, cartilage, adipose tissue, and connective tissue. The first findings in this respect are very old and date back to the observation that patients submitted to cancer chemotherapy showed significant improvement after they had received a red bone marrow cell transplant [12]. ASCs have been identified in many tissues and organs, such as brain, bone marrow, peripheral blood, blood vessels, skeletal muscle, skin, and liver [4,14]. Except for bone marrow, SCs seem to be present in small quantities in the other tissues $[13,15]$.

There is still no evidence that ASCs can differentiate into all types of tissues. Although ontogenically more developed than embryonic cells, ASCs may contain more DNA anomalies caused by errors in the ontogenic program that occur throughout life. However, these risks are lower than in the case of embryonic cells [13].

\subsection{Umbilical Cord Stem Cells}

SCs are also found in the umbilical cord. The classification of these cells is confusing. Some investigators refer to these cells as ASCs since the umbilical cord is generally obtained at birth. Others prefer to classify them as a variant of ESCs due to their origin. Nevertheless, the differentiation potential of umbilical cord SCs differs from that of ESCs. From a morphological viewpoint, cells present in the umbilical cord correspond to Wharton's jelly. In histology, the tissue present in the umbilical cord is called mucous tissue, a variant of connective tissue rich in mesenchymal cells [16]. Undifferentiated cells can also be found inside blood vessels or in the vessel wall. Human umbilical cord blood cells have specific application for the newborn itself and can be stored for future use, if necessary. These cells could eventually be used in identical twins or in other individuals with adequate human leukocyte antigen (HLA). Their application to incompatible patients simultaneously with immuno-suppressors may also be possible [13].

Umbilical cord SCs have been used as an alternative to bone marrow transplants, although the results are much more promising in children [2]. In addition, studies using experimental models have shown a potential of these cells to regenerate damaged tissues. The fact that umbilical cord cells are more easily obtained from a material that is usually discarded makes their use less controversial from an ethical point of view [1]. However, the extent to which differentiated cells can be obtained is limited. Two hypotheses have been raised to explain these findings: a) a lower differentiation potential of these cells, and b) researchers are still unable to manipulate these cells so that they develop their full differentiation potential.

\subsection{Bone Marrow Stem Cells}

Bone marrow stem cells (BMSCs), a variant of ASCs, are of special interest in regenerative medicine. There is substantial evidence indicating that BMSCs circulate to peripheral blood and back to the bone marrow in a physiological process that is closely regulated by the complex interaction of cytokines. The observation of cardiac chimerism after bone marrow transplantation may be explained in part by this phenomenon. Evidence indicates that SCs, possibly derived from bone marrow, circulate in peripheral blood and travel to damage tissues in hematological and non-hematological diseases. Furthermore, BMSCs are relatively easy to isolate and are therefore excellent candidates for regenerative therapies [12].

\subsection{Adipose Tissue Stem Cells}

Recent studies indicate that ASCs are also found in adipose tissue obtained by lipoaspiration [17]. This would be an interesting alternative in tissue engineering since the removal of adipose tissue due to esthetic reasons is widely accepted within the Brazilian population. Isolation of cells with a therapeutic potential from adipose tissue by lipoaspiration is a promising process since, once stimulated by different factors, these cells can differentiate into adipose cells, bone, cartilage, and muscle cells. These cells present advantages over bone marrowderived cells since the process of lipoaspiration under local anesthesia is less invasive and adipose tissue-derived mesenchymal cells are easily and abundantly obtained [18]. Studies comparing bone marrow- and adipose tissue-derived mesenchymal cells have shown that the two types of cells present a similar differentiation potential and similar cell surface markers $[12,17,18]$.

\subsection{Stem Cell Differentiation Pathways}

SC research is one of the major challenges in biomedical sciences: what does permit the long-term self-renewal of SCs and which factors regulate their proliferation and self-renewal? Differentiation is defined as the transformation of undifferentiated SCs into cells of adult tissue with a specific shape and function, whereas transdiffer- 
entiation takes place when a differentiated cell transforms into another type of cell [4]. According to some investigators, transdifferentiation also occurs when SCs of an organ or tissue form cells of another organ or tissue. However, this concept has not been universally accepted.

Studies have tried to identify the signals that cause SCs to proliferate and remain undifferentiated in the adult organism until they need to assume a certain function. In the case of ESCs, cell agglomerates form cell masses, called embryoid bodies. The spontaneous formation of cells and their differentiation into muscle and bone cells is observed in or around these bodies. The signals involved in this type of differentiation are still unknown [9].

In the case of ASCs, knowledge of the normal differentiation pathways is important to understand their differentiation potential for experimental or therapeutic use. Analysis of these pathways permits to characterize the microenvironment of these cells and to identify the factors to which they are exposed. Once we obtain a better understanding of the in vivo microenvironment of these cells, i.e., hormones and growth factors to which the cells are exposed, possible cell-cell interactions and extracellular matrix components, we may be able to induce the process of differentiation and direct the differentiation of cells into a desired type.

The use of SCs for in vitro tissue production processes, techniques known as tissue engineering, requires a growth scaffold that provides the necessary structural support and permits nutrient and oxygen transport. The growth substrate may consist of natural components such as extracellular matrix, or of synthetic elements such as lactic acid. The matrix components activate genes that control the pathways of differentiation and phenotype specification of growing cells. In this approach, the growth scaffolds are often bioresorbable, i.e., they are degraded and replaced with newly formed tissue [19]. Highly promising results have also been observed in vitro with the use of calcium phosphate ceramics. These ceramics (pore size ranging from 100 to $250 \mu \mathrm{m}$ ) have been shown to permit the adhesion, proliferation and differentiation of MSCs into osteogenic cells, and might be used as a scaffold in bone tissue engineering. In addition, the expression of bone differentiation markers, such as the BGLA and SSP1 genes, and alkaline phosphatase activity were demonstrated within 10 to 15 days of culture [20]. In vitro pre-differentiation followed by implantation seems to be a promising alternative in regenerative medicine.

The mechanisms underlying SC differentiation are still not completely understood. However, it is believed that substances secreted by neighboring cells and components of the microenvironment present in soluble form or bound to the extracellular matrix, such as growth factors, are involved in this process. Among these growth factors, five families seem to play a key role in the process of cell differentiation: bone morphogenetic proteins (BMPs), fibroblast growth factor (FGF), Hedgehog proteins (Hhs), wingless and int-related proteins (Wnts), and tumor necrosis factor (TNF) $[6,7,9,10,12]$.

\subsection{Therapeutic Applications of Adult Stem Cells}

The discovery that adult tissues contain pluripotent SCs gave rise to a series of studies since no ethical-religious or immunological issues are involved. The use of SC therapies for the repair of damaged tissues or organs in patients with chronic degenerative diseases is promising. In 1998, using an experimental model of muscle injury chemically induced in mice, demonstrated that BMSCs of adult animals, in this case, myogenic precursors, could migrate to the damaged region and differentiate into skeletal muscle [6]. This finding raised the interest in the therapeutic application of SCs. Even the field of plastic surgery has recently become interested in the topic and started to participate in SC research after adipose tissue and skin have become sources for the isolation and differentiation of SCs, opening new prospects for the reparative or esthetic treatment of congenital and acquired deformities [21].

These studies described above indicate a change in the paradigm in which precursor cells derived from bone marrow can repair post-mitotic tissues, i.e., tissues without regenerative capacity. Since the use of ASCs does not involve the same philosophical, ethical or religious issues as does the use of ESCs, the application of bone marrow-derived ASCs has opened new horizons in regenerative medicine. In this respect, since the cells are autologous, immune system rejection is unlikely and there is no need to store cells in tissue banks. Among the chronic degenerative diseases that could be treated with SCs, cardiovascular diseases have so far been the most extensively studied [1].

SCs directed to differentiate into specific cell types offer the possibility of a renewable source of replacement cells and tissues to treat various diseases. For cellbased therapy designed to treat degenerative and debilitating diseases, researcher need to be able to manipulate the cells easily and to reproduce them in such a way that they acquire the characteristics necessary for the successful transformation of transplants and grafts. Such cells should possess the following characteristics: a) to proliferate extensively and to generate sufficient amounts of tissue; b) to differentiate into the desired cell type; c) to survive in the recipient after transplantation; d) to integrate into the surrounding tissue after transplantation; e) to function appropriately throughout the recipient's life, and f) to avoid damage to the recipient in any way. 


\subsection{Cell Therapy in Orthopedics}

Progenitor cells produced by ASCs ameliorate endothelial injuries by promoting endothelial remodeling and thus preventing fibromuscular hyperplasia. A beneficial effect of progenitor cells on lipid metabolism balance has been reported. In addition, the number of these cells has been shown to increase with physical activity and the use of statins, but decreases in the presence of diabetes and chronic ischemic disease. With respect to tumors, the need for vascular proliferation to irrigate the rapidly growing tumor tissues results in the release of factors that mobilize bone marrow-derived ASCs. In this respect, antiangiogenic mechanisms would impair tumor growth [13].

For the mobilization of ASCs, stimuli are generated by substances secreted in the ischemic zone, such as VEGF, FGF, cytokines, angiopoietins, and others. Another possibility is that ASCs themselves produce these triggers that contribute to the formation of new vessels, also stimulating resident progenitor cells in the ischemic region (paracrine activity). In addition, these triggers improve endothelial function in remnant vessels and promote vasodilatation [22]. Important results have been provided by studies using experimental animals. Iba et al. [23] showed that circulating or bone marrow-derived mononuclear progenitor cells improved capillary density in models of limb ischemia. The authors observed that SCs promoted the formation of a collateral circulation by supplying angiogenic factors. Araujo et al. [13] detected higher expression of VEGF and increased endothelial differentiation in bone marrow cells pre-stimulated by extracorporeal hypoxia when compared to cells processed under normoxic conditions. Also in that study, implantation of bone marrow mononuclear cells into ischemic limbs induced the formation of new vessels, with the incorporation of progenitor cells into capillaries. Furthermore, the concentrations of FGF, VEGF and cytokines were increased in tissues of the implanted limb. In athymic rats, injection of heterologous progenitor cells incubated with VEGF increased the circulation more than in control animals (injection of progenitor cells and antibody against VEGF) [13].

There are also studies reporting the clinical experience with ASCs. In a pilot randomized trial conducted by Tateishi-Yuyama et al. [24], 47 patients were divided into two groups: group A consisted of 25 patients with unilateral critical leg ischemia and group B consisted of 22 patients with bilateral leg ischemia. In group $A$, bone marrow mononuclear cells were injected into the leg with critical ischemia and saline was injected into the contralateral leg. In group $\mathrm{B}$, bone marrow mononuclear cells were injected into one leg and peripheral blood mononuclear cells into the other leg. Most patients of the two groups injected with bone marrow mononuclear cells reported pain relief. Transcutaneous oxygen pressure improved significantly. At 6 months, angiography showed marked improvement of the collateral circulation in 15 patients of group A and in 12 of group $\mathrm{B}$. In one patient who died of myocardial infarction 3 months after implantation, histological analysis revealed a substantial increase of vascularization (muscle/capillary ratio) when compared to the limb injected with saline. Pain disappeared in 12 patients of group A and in 10 of group B, and improvement of rest pain was observed in 9 patients of group A and in 6 of group B. Amputation of the toes was avoided in 15 of 20 patients and ischemic ulcers improved in 6 of 10 patients. Less significant results were obtained for legs injected with peripheral blood mononuclear cells [24]. The authors suggested that the implanted cells secrete angiogenic factors and cytokines. However, the fact that blood levels of these factors do not increase after cell injection supports the suggestion of simultaneous administration of a combination of factors, i.e., VEGF to stimulate the formation of endothelial tubes and FGF to produce myoblasts for the maturation of newly formed vessels [13,22].

Despite these promising results, there are a series of important questions that need to be addressed to better understand and optimize the results obtained. First, the technique of SC isolation needs to be optimized. Comparison of the collection of rabbit bone marrow SCs from different regions revealed that a larger number of mononuclear cells can be harvested from the femoral epiphysis $\left(11.79 \times 10^{6}\right.$ cells $\left./ \mathrm{ml}\right)$, accompanied by a lower death rate of the animals, than from the iliac crest $\left(3.6 \times 10^{6}\right.$ cells $/ \mathrm{ml}$ ) [25]. Another study compared the effects of bone marrow-derived MSCs and human immature dental pulp SCs on osteonecrosis induced in the femoral head of sheep. The findings showed that MSCs injected into the femoral head were viable after transplantation and proliferated within a short period of time. The histological results suggested faster bone regeneration in animals transplanted with immature dental pulp compared to the control group (submitted only to central decompression) [26].

\subsection{Cell Therapy in Cardiology}

There are a considerable number of experimental studies investigating the use of SCs for myocardial regeneration. In a pioneering study in animals, Orlic et al. [27] suggested the differentiation of BMSCs into cardiomyocytes. Cells obtained from the bone marrow of male mice were injected directly into the myocardium of female mice through a transepicardial approach 3 to $5 \mathrm{~h}$ after occlusion of the coronary artery. Significant improvement of ventricular function parameters and ventricular wall thickness was observed in infarcted treated animals when compared to animals not treated with SCs, suggesting the 
formation of muscle fibers as a result of the procedure. The methods for implantation of SCs into the myocardium include intracoronary injection, transepicardial injection under direct visualization during open heart surgery, and transendocardial injection guided by electromechanical mapping of the heart.

In preliminary Brazilian studies, cells were collected from bone marrow of patients with chronic ischemic heart disease refractory to optimized clinical therapy in a study conducted in Rio de Janeiro. Another investigation conducted in Bahia used a model of chagasic cardiopathy, in which mice with chronic Chagas disease received intravenous injections of bone marrow mononuclear cells obtained from consanguineous mice. The results showed a significant reduction in the number of inflammatory cells and in the degree of myocardial fibrosis in treated animals compared to controls [1].

On the basis of these studies, a Phase 1 investigation involving patients with chronic idiopathic cardiomyopathy resulting from chagasic cardiopathy was started. Mononuclear cells were aspirated from various sites of the two iliac crests of the patients and directly injected into the coronary circulation through a catheter system after exclusion of coronary artery disease. The results obtained 6 months after treatment indicated significant improvement both in cardiac function and in the quality of life of the patient. Despite these promising results using bone marrow-derived cell therapies in cardiopathies, it remains unknown what types of cells are important for tissue repair. Similarly, it is still unknown how and which soluble factors participate in the recruitment and induction of differentiation of these cells after their implantation into the tissues that need to be repaired. Furthermore, the mechanism whereby SCs regenerate damaged tissues is still unclear [1].

One promising application of SCs is the treatment of chronic chagasic cardiopathy, a disease for which there is still no effective treatment. The disease is characterized by an inflammatory response that leads to the progresssive destruction of the myocardium, causing cardiomegaly and congestive heart failure and consequent death of the patient. For the study of bone marrow-derived SC therapy in chagasic cardiopathy, isogenic mice were infected with a Colombian Trypanosoma cruzi strain. Bone marrow cells were obtained from normal mice and intravenously injected into animals with chronic chagasic cardiopathy. Transplanted mice presented significant improvement of myocarditis 2 months after transplantation as a result of an increase in the apoptosis rate of inflammatory cells. Fibrosis decreased significantly and is therefore a reversible process. The causes of the improvement of inflammation and fibrosis after transplantation are still unclear and little is known about the mechanisms of regeneration mediated by SCs; for example, which type of cell in the bone marrow population is responsible for the therapeutic effect seen in chagasic cardiopathy [28]. The identification of the cell population responsible for the improvement of myocarditis is important for the understanding of the regeneration mechanisms and for the development of more refined intervention strategies using purified cells and/or specific factors. However, bone marrow cell therapy does not cure Chagas disease.

Two Brazilian studies also evaluated for the first time the safety and efficacy of cell transplantation into the myocardium of patients with heart failure due to Chagas disease. Twenty-eight patients received a bone marrowderived mononuclear cell transplant by coronary injection. The effects on left ventricular ejection fraction, functional capacity, quality of life, arrhythmias, and biochemical, immunological and neurohormonal factors were evaluated. There were no complications directly related to the procedure. During the same period, significant improvement was observed in functional class, quality of life, and 6 -min walk test. There were no alterations in markers of immune activation or neurohormonal markers. These data suggest that intracoronary injection of bone marrowderived cells is safe in patients with heart failure due to Chagas disease. However, the extent of the benefit seems to be discrete and needs to be confirmed in larger clinical trials $[29,30]$.

In a study on the treatment of refractory angina in nine patients who did not response to conventional therapies, Dallan et al. [31] combined transmyocardial laser revascularization with bone marrow-derived HSCs. The authors of the study expected a synergistic effect of the combination of the two therapies, with a consequent increase in tissue perfusion. Approximately 11 laser shots were applied over the lateral, inferior and posterior portions of the heart. SCs were obtained by bone marrow aspiration from the iliac crest and injected through the channels opened by the laser beam. Patients submitted to the procedure presented a lower angina score as well as a reduction of ischemic areas in the left ventricle. The ventricular ejection function was unchanged. There was no case of death due to complications related to the procedure. One important aspect of that study is the hypothesis raised by the authors that the combination of SCs and transmyocardial laser revascularization exerts a synergistic effect. One explanation for this probable synergism suggested by the study is that the laser mediates the recruitment of cytokines to the site of inflammation [31]. The procedure was considered safe for patients.

Since few studies have evaluated bone marrow mononuclear cell transplantation in dilated non-ischemic cardiomyopathy, Kalil et al. [32] investigated the intramyocardial implantation of these cells by minithoracotomy and reported the one-year follow-up results. Nine patients with 
dilated cardiomyopathy (functional class III/IV) and a left ventricular ejection fraction $<35 \%$ received bone marrow mononuclear cells into 20 sites of the left ventricular free wall. An echocardiogram and nuclear magnetic resonance imaging were performed. The latter method demonstrated discrete nonsignificant differences. Intramyocardial implantation of SCs into dilated cardiomyopathy is feasible and safe. There was early improvement of symptoms. Medium-term follow-up showed regression of left ventricular function, but continued improvement of quality of life and functional class [32].

SC implantation has also been combined with cardiac resynchronization therapy in patients with heart failure and dilated cardiomyopathy who presented areas of fibrosis. Twenty-five patients were studied. Epicardial resynchronization was performed and cell therapy consisted of the endocardial injection of CD34- and CD133-positive cells. After 24 months, $84.8 \%$ of the patients were still alive and mortality (15.2\%) was not related to the procedure. Less satisfactory results were obtained for patients submitted only to resynchronization therapy. The conclusion of that study was that combined SC therapy is a safe and adequate alternative for patients with heart failure and dilated cardiomyopathy [33].

Cardiology is probably the medical area in which SC therapy has yielded the most encouraging results. Although much still needs to be known about the use and safety of SC therapy, patients already benefit from this technology which has significantly improved the quality of life of affected individuals.

\subsection{Cell Therapy in Dentistry}

The regeneration of a dental organ is not simple since its development is determined by complex interactions and numerous growth factors. In addition, cell differentiation is related to morphological changes that occur during formation of the tooth germ. SCs derived from the dental pulp can be classified according to their origin into embryonic/fetal or adult/postnatal cells [34]. Evidence indicates that SCs derived from deciduous teeth are similar to those found in the umbilical cord. Using techniques involving the digestion of pulp tissue by an enzymatic process, populations of pulp SCs were first identified in the dental pulp of permanent teeth (dental pulp stem cells, DPSCs) [35] and later in the pulp of deciduous teeth (stem cells from human exfoliated deciduous teeth)[36]. Analysis of the behavior of these cells revealed the basic characteristics of other postnatal SC populations, including self-renewal and high proliferation and differentiation capacities [37].

In phenotypic characterization studies, BMSCs and DPSCs presented characteristics similar to those of fibroblasts, endothelial cells, smooth muscle cells, and osteoblasts. These cells expressed bone markers such as sialoprotein, alkaline phosphatase, type I collagen, and osteocalcin [35]. According to Liu et al. [38], DPSCs display a fibroblastic phenotype in terms of the pattern of proliferation and mineralizing activity. In support of this concept, both tissues are classified as mucous tissue in histology. DPSCs require an appropriate induction medium and a scaffold for cell growth.

Studies have demonstrated the formation of autologous bone tissue from DPSCs obtained from individuals older than 30 years, as well as the differentiation of these cells into odontoblasts. Markers are used for the identification of DPSCs since these cells reside at different sites within the tissue. Further studies are needed to investigate specific markers that could identify SC niches present in dental pulp in situ and to determine how these niches develop. SCs from human pulp and from the periodontal ligament might be associated with the microvasculature [39].

Calcium hydroxide-induced pulp regeneration has been shown to be mediated by Notch cell-cell signaling. The results were consistent to confirm that this signaling pathway controls the destination of pulp-derived SCs during pulp regeneration. Porcine dental pulp cells cultured and treated with a growth factor (BMP-2) were transplanted into canine pulpless teeth for the observation of odontoblast differentiation and dentin formation. The result was satisfactory since it confirmed the differentiation of pulp cells into odontoblasts for the formation of dentin [40,41].

In an in vitro study, Soares et al. [39] isolated MSCs from rat bone marrow and induced their differentiation into chondrogenic and osteogenic cells. The MSCs were encapsulated in two layers of synthetic matrix, shaped into a human condyle, and implanted into the back of immunodeficient rats. The formation of a condylar structure was observed 8 weeks after implantation. In another study, porcine MSCs were isolated and incubated for 10 days in culture medium with osteogenic supplement. The cells were then transplanted into surgically induced mandibular bone defects. After 6 weeks, the defects were found to be filled with tissue resembling trabecular bone. Further analysis showed that SCs derived from the periodontal ligament expressed various cementoblast and osteoblast markers. When transplanted into immunocompromised rats, these cells formed a structure resembling cementum/periodontal ligament [39].

Experiments on rats used primordial dental lamina instead of isolated SC populations in an attempt to generate a dental organ. The use of dental cells in the bud stage obtained from newborn rats, cultured for 6 days and transplanted into the back of immunodeficient rats, resulted in the formation of mature dental crowns. In a similar experiment determining whether dental rudiments in the bell stage also generate a dental organ, these rudi- 
ments were transplanted into a maxillary tooth-less region of adult rats. The formation of an ectopic tooth was observed after 26 days. This tooth was histologically normal as indicated by the presence of dentin, enamel, and periodontal ligament-like tissue [39].

Comparison of the proliferation and differentiation potential of BMSCs and DPSCs demonstrated a higher in vitro colony-forming efficiency for pulp-derived SCs $[35,41]$. Taken together, the results reported above highlight the difficulty in manipulating the factors involved in the development of a dental organ. In addition, the insertion and function of the organ formed need to be guaranteed.

\subsection{Cell Therapy in Rheumatology}

One of the first studies investigating the transplantation of HSCs for the treatment of autoimmune diseases was conducted in Brasil in 1996 on a patient with cryoglobulinemia. In another study carried out in 1999, HSCs transplantation was used for treatment of the same disease. Both studies reported favorable outcomes. Also in 1999, in preliminary studies, HSCs were transplanted into a patient with systemic sclerosis presenting cutaneous, pulmonary and digestive involvement, who received low-dose conditioning. Transient improvement of intestinal symptoms was observed; however, 3 months after transplantation the patient presented a hypertensive episode and resurgence of the intestinal symptoms, and the immunosuppressive conditioning regimen was repeated [42].

Most patients with rheumatic diseases receive autologous transplants of HSCs, which are mobilized from the bone marrow to peripheral blood with cyclophosphamide and granulocyte growth factor and obtained by positive selection on affinity columns, or unmanipulated cryopreserved cells. The conditioning regimens (pre-transplant immunosuppression) vary according to the type of disease [43]. One Brazilian project started in 2001 primarily used autologous unmanipulated HSCs and in vivo depletion of $\mathrm{T}$ cells for the treatment of severe forms of systemic lupus erythematosus and multiple sclerosis refractory to conventional therapy. Forty patients with multiple sclerosis, nine with type I diabetes mellitus, one with amyotrophic lateral sclerosis, two with pemphigus, and 18 patients with rheumatic diseases received HSC transplants [42]. The results obtained for systemic lupus erythematosus showed that eight patients included in the HSC protocol had glomerulonephritis refractory to immunosuppression. Reactivation of lupus nephritis was observed after several mobilization attempts and immunosuppression was reintroduced. Five of the six patients submitted to HSC transplantation presented acute renal failure concomitantly to the conditioning regimen. Two of these patients died as a consequence of conditioning associated with septicemia. Two of the four survivors achieved remission of nephritis 48 months after transplantation without the use of any immunosuppression. One patient had nephrotic syndrome secondary to diffuse proliferative lupus nephritis and achieved clinical and laboratory remission after transplantation. The other patient remained in remission for 2 years, but then suffered acute myocardial infarction followed by worsening of renal function, and immunosuppression had to be reintroduced [42,43].

Still in the studies described above, most high-risk patients and patients refractory to the best immunosuppressive therapy available presented significant improvement and progression of the disease could be interrupted without the use of immunosuppression after transplantation or mobilization. However, some questions about the therapeutic effects of SCs are important and need to be answered. The results are promising but there are major challenges. Importantly, many of the treatments are still experimental and are not available to the general population [44].

The current treatment of autoimmune diseases consists of the administration of anti-inflammatory drugs, immunosuppressors, and immunomodulatory drugs. In most cases, the outcomes of this treatment are favorable. However, some patients are resistant to treatment and administration of high doses of the drugs in these cases leads to destruction of the bone marrow. This fact has encouraged the use of HSCs for this type of diseases [45].

Most of the HSC transplantations performed today for the treatment of autoimmune diseases use autogenic SCs, which are mobilized from bone marrow to peripheral blood by growth factors administered to the patient. The patient's blood is collected and processed and mature cells are eliminated until a sufficient number of SCs are obtained. The patient is then submitted to radiotherapy and chemotherapy in order to destroy dividing cells, including immune cells. The treated blood is then administered to the patient through transfusion so that the SCs migrate to the bone marrow and start the process of differentiation into mature and functional cells [45]. In the case of autoimmune diseases, the transplanted HSCs destroy the autoimmune cells, create a new functional immune system, and reconstitute tissues damaged during the course of the disease. Two examples of autoimmune diseases that are the subject of HSC research are systemic lupus erythematosus and amyotrophic lateral sclerosis [45].

\section{CONCLUSION}

SCs offer good prospects for the treatment of a variety of diseases for which no cure exists so far, such as multiple 
sclerosis, muscle and brain injuries, heart diseases, Parkinson's disease, and rheumatic disorders. SC therapy is already applied in some fields with encouraging results, for example, for the treatment of cardiovascular diseases. Although the results obtained are promising, many doubts and uncertainties exist regarding the mechanisms of action of SCs, the importance of different cell populations, and the factors necessary for the recruitment and function of these cells in vitro and in vivo. A better understanding of these phenomena will surely contribute to the development of more effective and less invasive therapeutic strategies.

\section{ACKNOWLEDGEMENTS}

We would like to thank the Brazilian government agencies CNPq and INCT-BIOFABRIS.

\section{REFERENCES}

[1] Mota, A.C.A., Soares, M.B.P. and Santos, R.R. (2005) Uso de terapia regenerativa com células-tronco da medula óssea em doenças cardiovasculares: perspectiva do hematologista. Revista Brasileira de Hematologia e Hemoterapia, 27, 126-132. doi:10.1590/S1516-84842005000200012

[2] Soncini, M., Virtua, E., Gibelli, L., Zorzi, F., Denegri, M., Albertini, A., et al. (2007) Isolation and characterization of mesenchymal cells from human fetal membranes. Journal of Tissue Engineering and Regenerative Medicine, 1, 296-305. doi:10.1002/term.40

[3] Santos Jr., A.R., Wada, M.L.F. and Carvalho, H.F. (2007) Diferenciação cellular. In: Carvalho, H.F., Recco-Pimentel, S.M., Eds., A Célula, 2nd Edition, Manole, São Paulo, 348-363.

[4] Bajada, S., Mazakova, I., Richardson, J.B. and Ashammakhi, N. (2008) Updates on stem cells and their applications in regenerative medicine. Journal of Tissue Engineering and Regenerative Medicine, 2, 169-183. doi:10.1002/term.83

[5] Bydlowski, S.P., Debes, A.A., Maselli, L.M.F. and Janz, F.L. (2009) Características biológicas das células-tronco mesenquimais. Revista Brasileira de Hematologia e Hemoterapia, 31, 25-35. doi:10.1590/S1516-84842009005000038

[6] Zago, M.A. and Covas, D.T. (2007) Células-tronco: A nova fronteira da medicina. Atheneu, São Paulo.

[7] Rodini, C.O., Suzuki, D.E., Nakahata, A.M., Pereira, M.C.L., Janjoppi, L., Toledo, S.R.C. and Okamoto, O.K. (2010) Aberrant signaling pathways in medulloblastomas: A stem cell connection. Arquivos de Neuro-psiquiatria, 68, 947-952. doi:10.1590/S0004-282X2010000600021

[8] Gilbert, S.F. (2010) Developmental biology. 9th Edition, Sinauer Associates, Sunderlan.

[9] Smith, A. (2001) Embryonic stem cells. In: Marshak, D.R., Gardner, R.L. and Gottlieb, D., Eds., Stem Cell Biology, Cold Spring Harbor, New York, 205-230.
[10] Lodish, H., Berk, A., Matsudaira, P., Kaiser, C.A., Krieger, M., Scott, M.P., et al. (2005) Molecular cell biology. 5th Edition, W.H. Freeman and Co., New York.

[11] Alberts, B., Johnson, A., Lewis, J., Raff, M., Roberts, K. and Walter, P. (2008) Molecular biology of the cell. 5th Edition, Garland Science, New York.

[12] Pittenger, M.F. and Marshak, D.R. (2001) Mesenchymal stem cells of human adult bone marrow. In: Marshak, D.R., Gardner, R.L. and Gottlieb, D., Eds., Stem Cell Biology, Cold Spring Harbor, New York, 349-373.

[13] Araujo, J.D., Araujo Filho, J.D., Ciorlin, E., Ruiz, M.A., Ruiz, L.P., Greco, O.T., et al. (2005) Terapia celular no tratamento da isquemia crítica dos membros inferiores. Jornal Vascular Brasileiro, 4, 357-365. doi:10.1590/S1677-54492005000400011

[14] Williams, J.T., Southerland, S.S., Lucas, P.A., Souza, J.W., Calcutt, A.F. and Cartledge, R.G. (1999) Cells isolated from adult human skeletal muscle capable of differentiating into multiple mesodermal phenotypes. American Surgeon, 65, 22-26.

[15] Panicker, M.M. and Rao, M. (2001) Stem cells and neurogenesis. In: Marshak, D.R., Gardner, R.L. and Gottlieb, D., Eds., Stem Cell Biology, Cold Spring Harbor, New York, 399-438.

[16] Junqueira, L.C. and Carneiro, J. (2008) Histologia básica, 11th Edition, Guanabara Koogan, Rio de Janeiro.

[17] Mazzetti, M.P.V., Oliveira, I.S., Miranda-Ferreira, R., Fauaz, G., Ribeiro, C.N., Gomes, P.O., Pontes, P., Ferreira, A.T. and Eça, L.P. (2010) Qualitative and quantitative analysis of rabbit's fat mesenchymal stem cells. Acta Cirúrgica Brasileira, 25, 24-27. doi:10.1590/S0102-86502010000100007

[18] Mizuno, H. and Hyakusoku, H. (2003) Mesogenic potential and future clinical perspective of human processed lipoaspirate cells. Journal of Nippon Medical School, 70, 300-306. doi:10.1272/jnms.70.300

[19] Santos Jr., A.R. and Wada, M.L.F. (2007) Polímeros biorreabsorvíveis como arcabouços para cultura de células e engenharia tecidual. Polímeros Ciência e Tecnologia, 17, 308-317. doi:10.1590/S0104-14282007000400010

[20] Silva, T.S.N., Primo, B.T., Silva Jr., A.N., Machado, D.C., Viezzer, C. and Santos, L.A. (2011) Use of calcium phosphate cement scaffolds for bone tissue engineering: In Vitro Study. Acta Cirúrgica Brasileira, 26, 7-11. doi:10.1590/S0102-86502011000100003

[21] Gomes, R.S. (2011) Perspectivas do uso de células-tronco em cirurgia plástica. Revista Brasileira de Cirurgia Plástica, 26, 151-159. doi:10.1590/S1983-51752011000100027

[22] Reis, P.E.O. (2005) Bone marrow stem cells and their role in angiogenesis. Jornal Vascular Brasileiro, 4, 366370. doi:10.1590/S1677-54492005000400012

[23] Iba, O., Matsubara, H., Nozawa, Y., Fujiyama, S., Amano, K., Mori, Y., et al. (2002) Angiogenesis by implantation of peripheral blood mononuclear cells and platelets into ischemic limbs. Circulation, 106, 2019-2025. doi:10.1161/01.CIR.0000031332.45480.79

[24] Tateishi-Yuyama, E.T., Matsubara, H., Murohara, T., 
Ikeda, U., Shintani, S., Masaki, H., et al. (2002) Therapeutic angiogenesis for patients with limb ischaemia by autologous transplantation of bone-marrow cells: A pilot study and a randomized controlled trial. Lancet, 360, 427435. doi:10.1016/S0140-6736(02)09670-8

[25] Eça, L.P., Ramalho, R.B., Oliveira, I.S., Gomes, P.O., Pontes, P., Ferreira, A.T. and Mazzetti, M.P.V. (2009) Comparative study of technique to obtain stem cells from bone marrow collection between the iliac crest and the femoral epiphysis in rabbits. Acta Cirúrgica Brasileira, 24, 400-404. doi:10.1590/S0102-86502009000500011

[26] Feitosa, M.L.T., Fadel, L., Beltrão-Braga, P.C.B., Wenceslau, C.V., Kerkis, I., Kerkis, A., Birgel Jr., E.H.B., Martins, J.F.P., Maritns, D.S., Miglino, M.A. and Ambrósio, C.E. (2010) Successful transplant of mesenchymal stem cells in induced osteonecrosis of the ovine femoral head. Preliminary results. Acta Cirúrgica Brasileira, 25, 416-422. doi:10.1590/S0102-86502010000500006

[27] Orlic, D., Kajstura, J., Stefano, C., Jakoniuk, I., Anderson, S.M., Li, B., et al. (2001) Bone marrow cells regenerate infarcted myocardium. Nature, 410, 701-705. doi:10.1038/35070587

[28] Santos, R.R., Soares, M.B.P. and Carvalho, A.C.C. (2004) Transplante de células da medula óssea no tratamento da cardiopatia chagásica crônica. Revista da Sociedade Brasileira de Medicina Tropical, 37, 490-495. doi:10.1590/S0037-86822004000600012

[29] Vilas-Boas, F., Feitos, G.S., Soares, M.B.P., Mota, A., Pinho-Filho, J.A., Almeida, A.J.G., Andrade, M.V., Carvalho, H.G., Dourado-Oliveira, A. and Ribeiro-dos-Santos, R. (2006) Resultados iniciais do transplante de células de medula óssea para o miocárdio de pacientes com insuficiência cardíaca de etiologia chagásica. Arquivos Brasileiros de Cardiologia, 87, 159-166. doi:10.1590/S0066-782X2006001500014

[30] Vilas-Boas, F., Feitosa, G.S., Soares, M.B.P., Pinho-Filho, J.A., Mota, A.C.A., Almeida, A.J.G., Andrade, M.V., Carvalho, H.G., Oliveira, A.D. and Ribeiro-dos-Santos, R. (2011) Transplante de células da medula óssea na insuficiência cardíaca chagásica: Relato da primeira experiência humana. Arquivos Brasileiro de Cardiologia, 96, 325-331. doi:10.1590/S0066-782X2011005000028

[31] Dallan, L.A.O., Gowdak, L.H., Lisboa, L.A.F., Schettert, J.E., Krieger, J.E., Cesar, L.A.M., Oliveira, S.A. and Stolf, N.A.G. (2008) Terapia celular associada à revascularização transmiocárdica laser como proposta no tratamento da angina refratária. Revista Brasileira de Cirurgia Cardiovascular, 23, 46-52. doi:10.1590/S0102-76382008000100009

[32] Kalil, R.A.K., Ott, D., Sant'Anna, R., Dias, E., MarquesPereira, J.P., Delgado-Cañedo, A., Nardi, N.B., Sant'Anna, J.R.M., Prates, P.R. and Nesralla, I. (2008) Autologous transplantation of bone marrow mononuclear stem cells by mini-thoracotomy in dilated cardiomyopathy: Technique and early results. Sao Paulo Medical Journal, 126, 75-81. doi:10.1590/S1516-31802008000200003

[33] Greco, O.T., Greco, R.L., Abreu, A.C., Jacob, J.L.B., Ardito, R.V., Takeda, R.T., Parro Jr., A., Sallis, F.V., Lago, M.R. and Ruiz, M.A. (2009) Ressincronização cardíaca e terapia celular: Existe terapia associativa? Revista
Brasileira de Hematologia e Hemoterapia, 31, 93-98. doi:10.1590/S1516-84842009005000025

[34] Fortier, L.A. (2005) Stem cells: Classifications, controversies, and clinical applications. Veterinary Surgery, 34, 415-423. doi:10.1111/j.1532-950X.2005.00063.x

[35] Gronthos, S., Mankani, M., Brahim, J., Robey, P.G. and Shi, S. (2000) Postnatal human dental pulp stem cells (DPSCs) in vitro and in vivo. Proceedings of National Academic of Science of USA, 97, 13625-13630. doi:10.1073/pnas.240309797

[36] Miura, M., Gronthos, S., Zhao, M., Lu, B., Fisher, L.W., Robey, P.G., et al. (2003) SHED: Stem cells from human exfoliated deciduous teeth. Proceedings of National Academic of Science of USA, 100, 5807-5812. doi:10.1073/pnas.0937635100

[37] Gronthos, S., Brahim, J., Li, W., Fisher, L.W., Cherman, N., Boyde, A., et al. (2002) Stem cell properties of human dental pulp stem cells. Journal of Dental Research, 81, 531-535. doi:10.1177/154405910208100806

[38] Liu, J., Jin, T., Ritchie, H.H., Smith, A.J. and Clarkson, B.H. (2005) In Vitro differentiation and mineralization of human dental pulp cells induced by dentin extract. In Vitro Cellular and Developmental Biology Animal, 41, 232238. doi:10.1290/0502014.1

[39] Soares, A.P., Knop, L.A.H., Jesus, A.A. and Araújo, T.M. (2007) Células-tronco em odontologia. Revista Dental Press de Ortodontologia e Ortopedia Facial, 12, 33-40. doi:10.1590/S1415-54192007000100006

[40] Lovschall, H., Tummers, M., Thesleff, I., Fuchtbauer, E.M. and Poulsen, K. (2005) Activation of the Notch signaling pathway in response to pulp capping of rat molars. European Journal of Oral Science, 113, 312-317. doi:10.1111/j.1600-0722.2005.00221.x

[41] Demarco, F.F., Conde, M.C.M., Cavalcanti, B.N., Casagrande, L., Sakai, V.T. and Nör, J.E. (2011) Dental pulp tissue engineering. Brazilian Dental Journal, 22, 3-13.

[42] Voltarelli, J.C., Stracieri, A.B.P.L., Oliveira, M.C.B., Godoi, D.F., Moraes, D.A., Pieroni, F., Malmegrim, K.C.R., Coutinho, M.A., Simões, B.P., Massumoto, C., Hamerschlak, N., Scheinberg, M., Ferreira, E., Coutinho, M., Ostronoff, M., Sturaro, D. and Dulley, F. (2005) Transplante de células-tronco hematopoéticas em doenças reumáticas parte 2: Experiência brasileira e perspectivas futuras. Revista Brasileira de Reumatologia, 45, 301-312. doi:10.1590/S0482-50042005000500004

[43] Voltarelli, J.C., Stracieri, A.B.P.L., Oliveira, M.C.B., Godoi, D.F., Moraes, D.A., Pieroni, F., Malmegrim, K.C.R., Coutinho, M.A. and Simões, B.P. (2005) Transplante de células-tronco hematopoéticas em doenças reumáticas parte 1: Experiência internacional. Revista Brasileira de Reumatologia, 45, 229-241. doi:10.1590/S0482-50042005000400007

[44] Pereira, L.V. (2008) A importância do uso das células tronco para a saúde pública. Ciência \& Saúde Coletiva, 13, 7-14. doi:10.1590/S1413-81232008000100002

[45] Rosa, S.B., Voltarelli, J.C., Chies, J.A.B. and Pranke, P. (2007) Use of stem cells in autoimmune diseases. Brazilian Journal of Medical and Biological Research, 40, 1579-1597. doi:10.1590/S0100-879X2006005000165 